\title{
PROGRAMA ARQUITETURA PÚBLICA DA ESCOLA DE ARQUITETURA DA UFMG - O CASO DE SANTO ANTÔNIO DO AMPARO
}

\author{
PUBLIC ARCHITECTURE PROGRAM OF THE ESCOLA DE ARQUITETURA DA UNIVERSIDADE \\ FEDERAL DE MINAS GERAIS - THE SANTO ANTÔNIO DO AMPARO CASE
}

\section{MACIEL , Marieta Cardoso}

Arquiteta e urbanista, professora doutora do Departamento de Projeto da Escola de Arquitetura da UFMG. E-mail: marietamaciel@hotmail.com

\section{SIMÃO, Karina Machado de Castro}

Arquiteta e urbanista, bolsista do Programa Arquitetura Pública da Escola de Arquitetura da UFMG.

E-mail:karinadecastro@gmail.com

\section{PERNA, Stefânia de Araújo}

Arquiteta e urbanista, bolsista do Programa Arquitetura Pública da Escola de Arquitetura da UFMG.

E-mail:stefaniap@pop.com.br

\section{RESUMO}

Este documento mostra o anteprojeto de revitalização da praça Matriz do município de Santo Antônio do Amparo, realizado no âmbito do Programa de Extensão Arquitetura Pública da Escola de Arquitetura da Universidade Federal de Minas Gerais, no período de setembro a dezembro de 2005.

Para a realização do projeto, foram elaborados uma coleta de dados, entrevistas com os moradores, e levantamentos em campo para uma análise da situação, e posterior diagnóstico do lugar. A partir dessa análise, foram feitas várias pesquisas de casos análogos e estudos preliminares de proposta. Esses estudos foram apresentados à prefeitura e à comunidade do município e, após algumas sugestões e discussões a respeito da proposta, foi realizado o anteprojeto de revitalização do espaço. Ou seja, a comunidade envolvida participou tanto do processo de elaboração quanto de aprovação do projeto.

O programa possibilitou o aprendizado através de experiências com a realidade: o contato com o cliente e com o problema.

Palavras-chave: Revitalização, paisagismo, espaço público.

\begin{abstract}
This paper presents the Project of the main square of the city Santo Antônio do Amparo, realized in the scope of the Public Architecture Program of the Architecture School of Federal University of Minas Gerais, in the period of during September to December's 2005 (two thousand and five).

To realize the project, local researches and them diagnosis of the area were made. Then, a lot of researches of similar projects and studies were realized. Those studies were presented to the municipal mayor and the community, and after some suggestions, the final project were made.

The Program possibilited the learning by the reallity experiences: the contact with the client and with the problem.
\end{abstract}

Key words: Revitalization, landscape, public space.

\section{Introdução}

O Programa de Arquitetura Pública é um conjunto de projetos que visam permitir aos estudantes de arquitetura e urbanismo uma maior integração do ensino acadêmico com a prática profissional, ao mesmo tempo em que contribui para o desenvolvimento do país, aproximando a Universidade da sociedade através da prestação de serviços de interesse social e responsabilidade ambiental. 
O programa tem uma formatação diversificada que envolve ensino, pesquisa e extensão, é uma típica atividade extensionista desenvolvida pela Escola de Arquitetura através de dois de seus órgãos, o Centro de Tecnologia e Prestação de Serviço - CETEPS, ligado ao Departamento de Tecnologia da Arquitetura e Urbanismo - TAU, e o Centro de Pesquisa e Extensão - CEPEX, ligado à diretoria. Iniciou-se no $2^{0}$ semestre de 2004, quando foram implementados os projetos de arquitetura pública de Sabará, lagoas da Prata e Cataguases, além dos projetos de Santana de Cataguases, Barbacena, Santo Antônio do Amparo, Minas Novas e Pitangui, que começaram em 2005.

Programa tem uma formatação diversificada que envolve ensino, pesquisa e extensão e é organizado em projetos-piloto que utilizam como base as demandas urbanas, sociais e culturais das prefeituras dos municípios mineiros no que diz respeito aos serviços de arquitetura e urbanismo. Os principais enfoques do programa são habitação de interesse social, planejamento urbano e patrimônio cultural.

Enfim, o Programa Arquitetura Pública, com a colaboração de técnicos de Prefeitura, além de prestar serviços técnicos à população de baixa renda, presta serviços à população como um todo na medida em que auxilia o município em sua política de planejamento urbano e preservação do importante patrimônio cultural da cidade, tombado nacionalmente ou não, desde que tenha relevância local.

O programa no município de Santo Antônio do Amparo atende à demanda prioritária da Prefeitura: revitalizar as praças que circundam a Igreja Matriz da cidade.

Santo Antônio do Amparo está localizado no sul de Minas, no alto do Rio Grande, no Campo das Vertentes. A população do município é de 16.605 habitantes e a espaço de aproximadamente $493 \mathrm{~km}^{2}$, sendo a densidade demográfica de $32 \mathrm{hab} . / \mathrm{Km}^{2}$. A altitude média é de 982 m e a temperatura anual $19,9^{\circ} \mathrm{C}$. A distância do município ao centro de Belo Horizonte é de 172 km e ao centro de São Paulo é de 400 km.

A denominação do município de Santo Antônio do Amparo deve-se a dois motivos, um religioso e outro por servir a localidade, de amparo aos viajantes e tropeiros que passavam pela região, até então habitada por índios, dos quais ainda são encontrados muitos vestígios.

O sul de Minas é hoje conhecido mundialmente, sendo o principal produtor de café no mundo, sendo que o município de Santo Antônio do Amparo participa e colabora desse privilégio. Durante os períodos de colheita, os proprietários locais de café costumam empregar homens e mulheres, garantindo o futuro de muitas famílias e o crescimento da cidade.

A estrada BR-381 (Fernão Dias) marca o início do município, a partir da qual é possível observar as grandes palmeiras e a torre da Igreja Matriz, localizadas na área central (ponto mais alto da cidade). Dessa forma, podemos considerar o centro municipal o marco da morfologia urbana de Santo Antônio do Amparo.

As praças Governador Valadares e Joaquim Ferreira estão localizadas nessa área central e fazem parte do conjunto do largo da Igreja Santo Antônio do Amparo (Matriz). Em conjunto com o desenho da paisagem urbana, essas praças desempenham um papel de agente de conexão entre as partes da cidade e o espaço livre público, sendo de grande importância para a população.

A localização das praças contribui para que o local esteja em constante uso, sendo observada claramente, durante o cotidiano, a relação de diálogo entre os cidadãos de Santo Antônio do Amparo e as praças Governador Valadares e Joaquim Ferreira.

Um dos motivos da escolha dessas praças como espaço a ser modificado é justamente o fato delas serem usadas por vários agentes e atores do espaço urbano, em diversos horários e para as mais variadas funções. Essas são espaços centralizadores na cidade, que concentram 


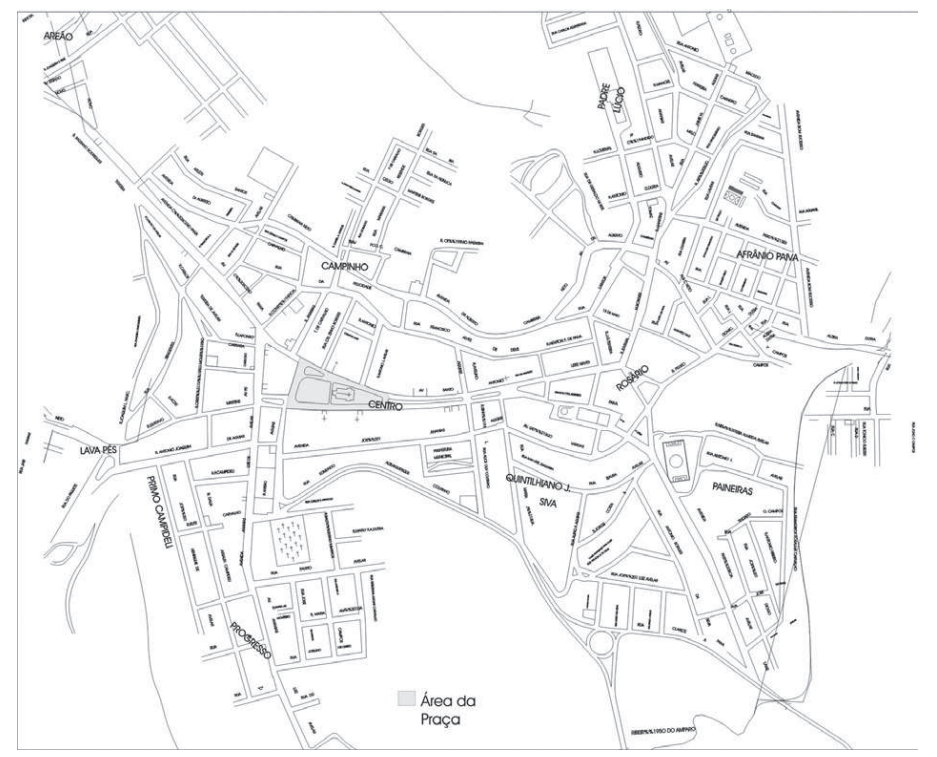

Figura 1: Localização das praças no município

Fonte: Prefeitura de Santo Antônio do Amparo

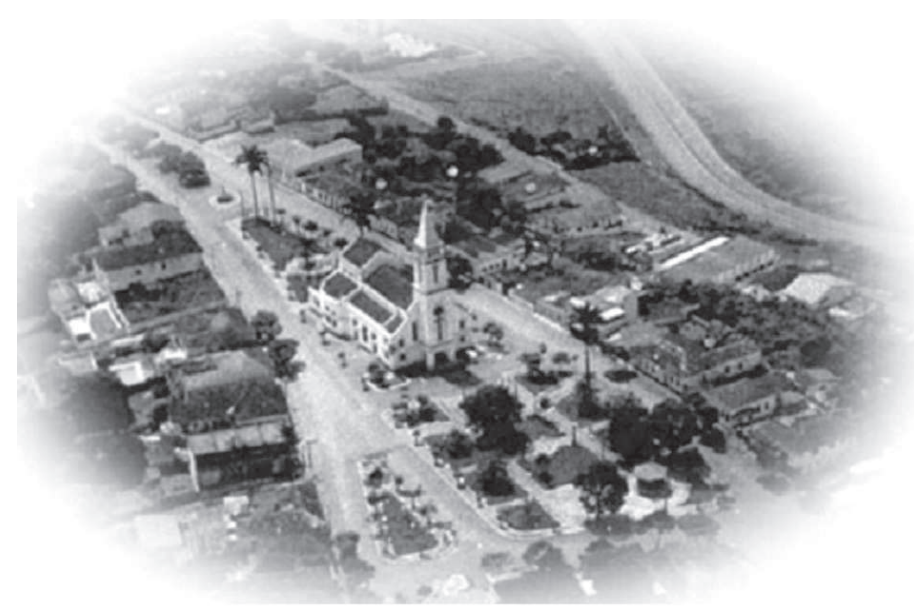

Figura 2: Igreja Matriz e praças Governador Valadares e Joaquim Ferreira (vista aérea)

Fonte: http://www.geocities.com, em outubro de 2005

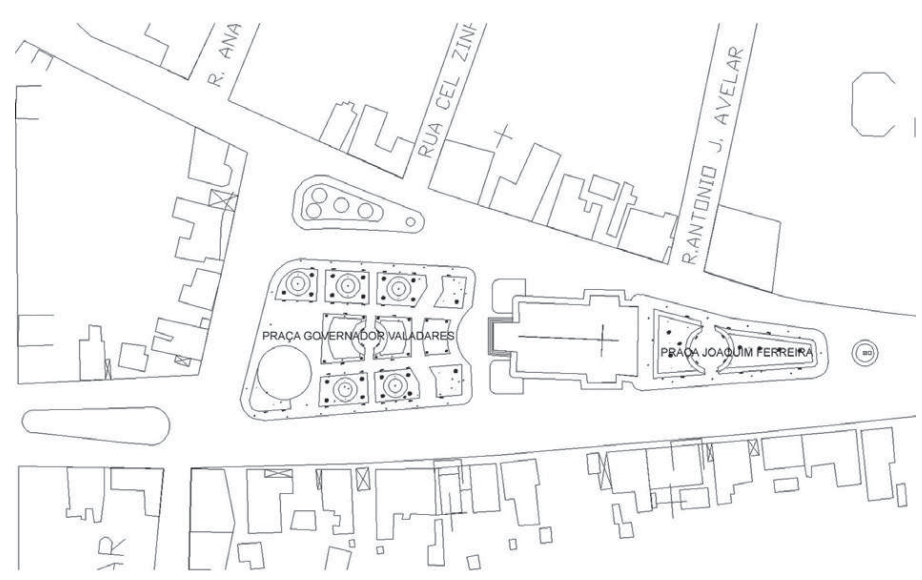

Figura 3: Planta das praças Governador Valadares e Joaquim Ferreira atual

Fonte: Karina Machado e Stefânia Perna

diversas atividades (serviços, comércio, lazer, encontros, entre outros). Portanto, podem ser consideradas o marco e referência principal de Santo Antônio de Amparo.

200 Robba e Macedo partem do conceito que "praças" são espaços livres públicos urbanos destinados ao lazer e ao convívio da população, acessíveis aos cidadãos e livres de veículos.

A praça, juntamente com a rua, consiste em um dos mais importantes espaços públicos urbanos da historia da cidade no país, tendo, desde os primeiros tempos da colônia, desempenhado um 
papel fundamental no contexto das relações sociais em desenvolvimento. De simples terreiro a sofisticado jardim, de campo de jogos incultos a centro esportivo complexo, a praça é, por excelência, um centro, um ponto de convergência da população, que ela ocorre para o ócio, para comerciar, para trocar idéias, para encontros românticos ou poíticos, enfim, para o desempenho da vida urbana ao ar livre.

Inúmeras são as definições referentes ao termo praça. Mesmo havendo divergências entre os autores, todos concordam em conceituá-la como um espaço público e urbano. A praça sempre foi celebrada como um espaço de convivência e lazer dos habitantes urbanos.

Ao longo dos tempos, com a evolução das cidades, alterou-se significativamente o papel da praça na urbe, todavia, o caráter social que sempre a caracterizou, permaneceu e permanece como sua mais intrínseca qualidade.

\section{Histórico}

A antiga lgreja da Matriz foi construída por volta de 1730 e era situada em um ádrio (piso elevado), onde as pessoas eram enterradas. A igreja era uma simples capela com um altar, não havia torre e posteriormente foi sendo ampliada, adquirindo um tamanho aproximadamente três vezes maior do que o original, sendo também construído um campanário na sua lateral direita.

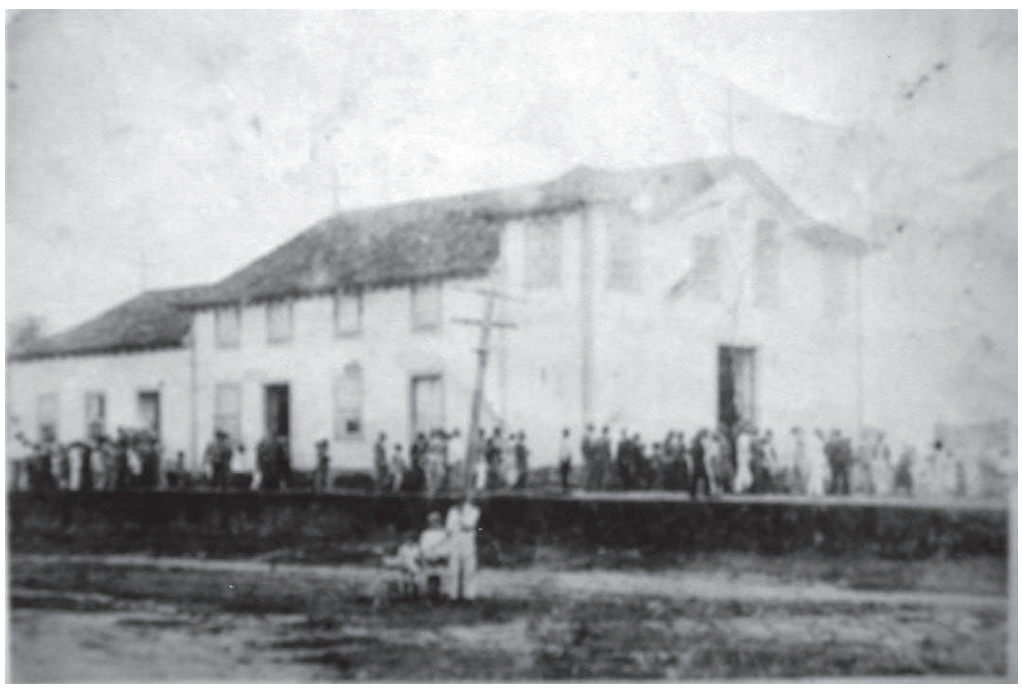

Figura 4: Igreja da Matriz, construída em 1730

Fonte: Pedro Alves Avelar

Nessa época a igreja era circundada apenas por piso de terra, não havia jardim nem vegetações de grande porte, mas mesmo assim o local já era utilizado para realização de festas, procissões, entre outros, sendo que a área frontal da igreja (maior, situada no terreno em declive - atual praça Governador Valadares) era utilizada pelas pessoas da elite e a área dos fundos (menor, situada no terreno em aclive - atual praça Joaquim Ferreira) era utilizada pelos escravos e negros.

Por volta de 1933 a antiga igreja Matriz foi demolida. Para a construção da atual igreja, o ádrio foi desaterrado e os restos mortais foram transferidos para o novo cemitério (também construído). Com a nova obra, o sino foi transferido para a torre (aproveitando os andaimes da construção), não existindo mais o campanário.

Em 1939 o prefeito do município, Gustavo Martins, contratou um engenheiro alemão para realizar o calçamento da cidade (em paralelepípedos irregulares) e o projeto do jardim da igreja Matriz. O jardim tinha duas escadas laterais na praça Governador Valadares, feitas com a pedra bruta da antiga igreja, e uma fonte circular no centro. A praça Joaquim Ferreira possuía dois canteiros laterais, marcando um eixo central. $O$ coreto era separado da praça, localizado próximo à lateral direita da nova igreja Matriz. $\bigcirc$ estilo eclético clássico das praças era condizente com o estilo da igreja Matriz (†ambém eclético). 

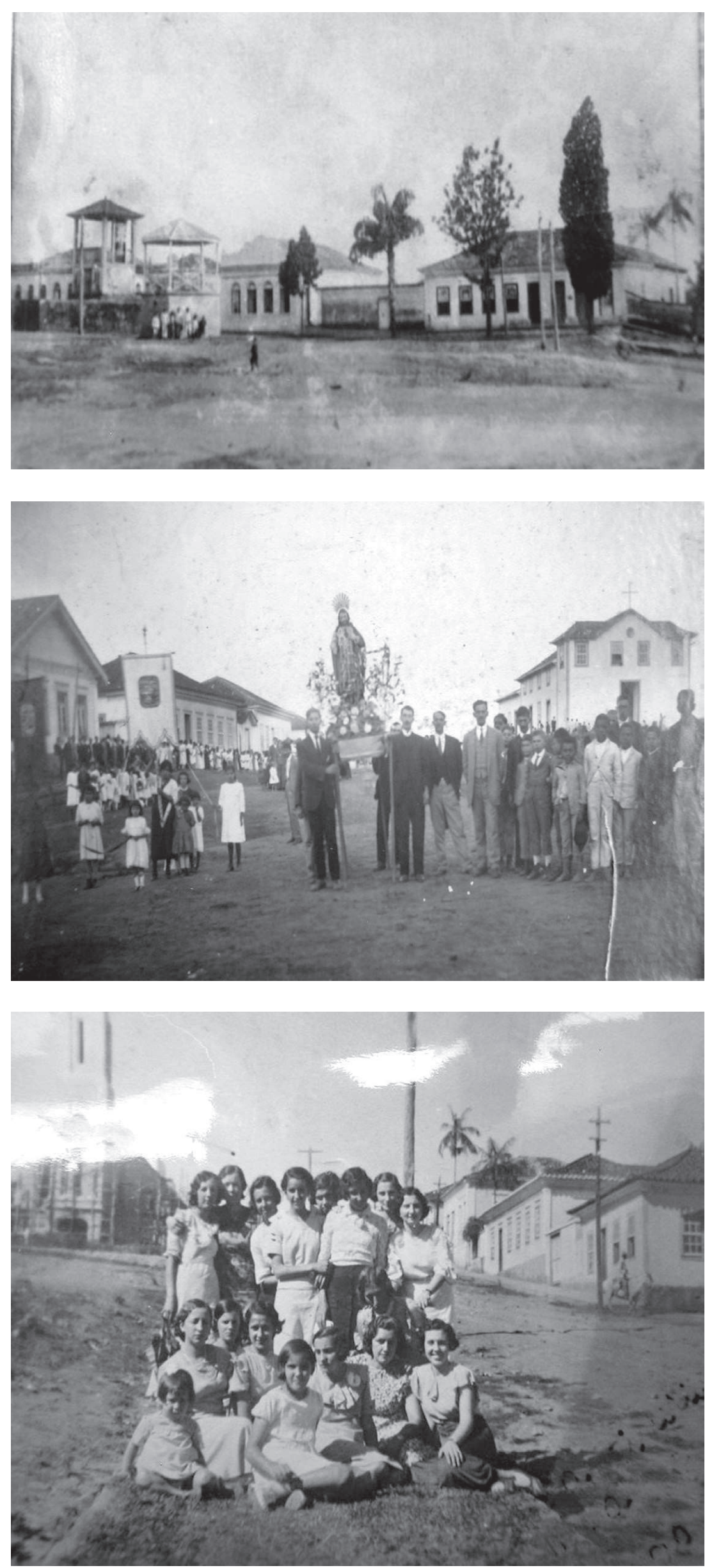

Figura 5: Vista do Coreto da praça (aproximadamente na década de 1920)

Fonte: Pedro Alves Avelar

Figura 6: Rua Santo Antônio com a Igreja da Matriz (antiga), ao fundo (aproximadamente na década de 1920)

Fonte: Pedro Alves Avelar

Figura 7: Rua Santo Antônio e a lgreja da Matriz (atual, em construção), ao fundo (aproximadamente na década de 1930)

Fonte: Pedro Alves de Avelar 
Essa praça, concebida em 1939, tem as características da linha eclética clássica:

- Traçado em cruz e variações;

- Estar central com ponto focal;

- Passeio perimetral;

- Canteiros geométricos;

- Simetria;

- Eixos;

- Grande quantidade de áreas permeáveis;

- Elementos ecléticos pitorescos, como coreto e fonte;

- Vegetação arbustiva e forrações, dispostas como bordadura dos canteiros e caminhos;

- Vegetação arbórea plantada ao longo dos caminhos para sombreamento;

- Geometria e simetria no plantio da vegetação.

Esse traçado eclético estava associado a uma forma de utilização do espaço condizente com o momento de sua idealização:

- Passeio;

- Contemplação da natureza;

- Convívio Social;

- Cenário.

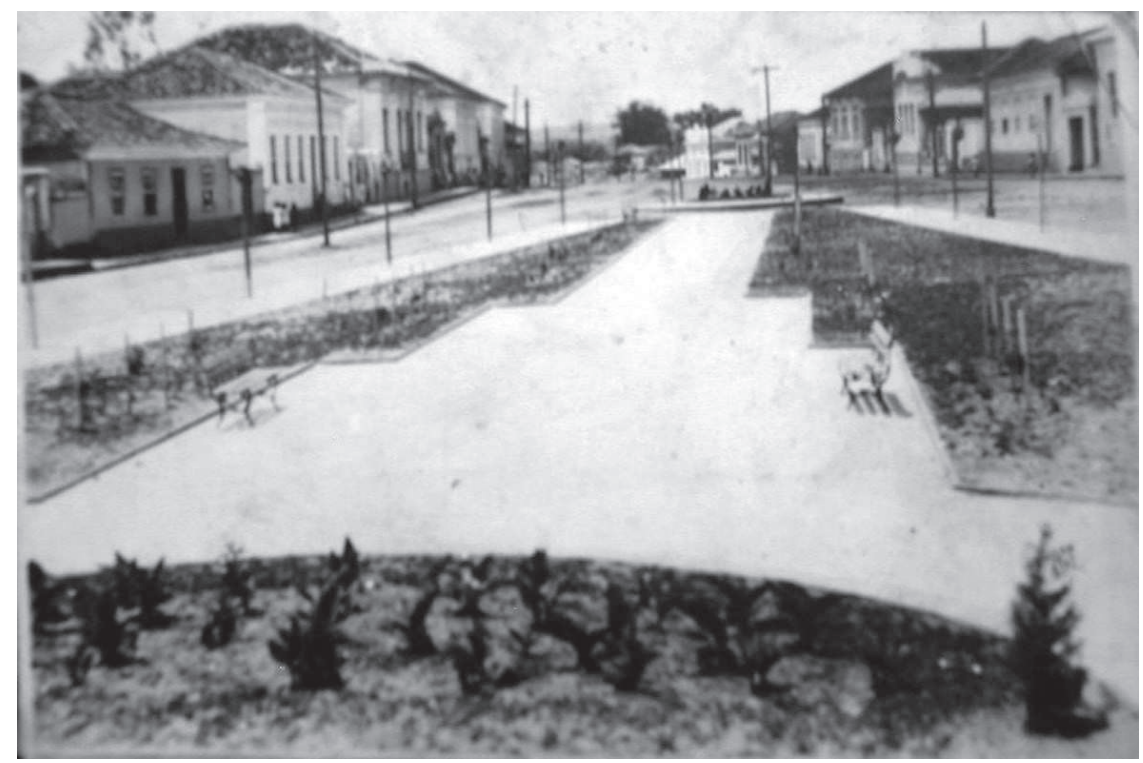

Figura 8: Praça Joaquim Ferreira por volta de 1939 Fonte: Pedro Alves Avelar

Após essa data, a praça sofreu algumas modificações, mas mantendo as características da linha eclética clássica. Na praça Joaquim Ferreira, o eixo ganha uma marcação em forma de círculo no meio da praça menor, e os canteiros laterais agora são mais recortados. A praça Governador Valadares teve a fonte central retirada e substituída por marcação de piso.

Em 1995, o paisagista César Bontempo foi contratado para fazer o projeto de revitalização da praça, cujas características (ainda de estilo eclético clássico) podem ser observadas até hoje. $\mathrm{Na}$ praça Governador Valadares foram mantidos os canteiros, sendo alteradas as escadas (†ornaram-se rampas), feita uma nova distribuição de vegetação, a inserção de o mobiliário urbano e a paginação do piso. A situação do coreto foi modificada, passando a fazer parte dessa praça.

A praça da Matriz continua tendo grande importância para o município de Santo Antônio do Amparo, sendo bastante utilizada pelos seus moradores, principalmente nos fins de semana. Geralmente ela é ocupada pelos jovens da cidade nas sextas feiras à noite e pelas famílias durante as manhãs dos sábados, quando ocorre a feira próxima à Casa da Cultura. 


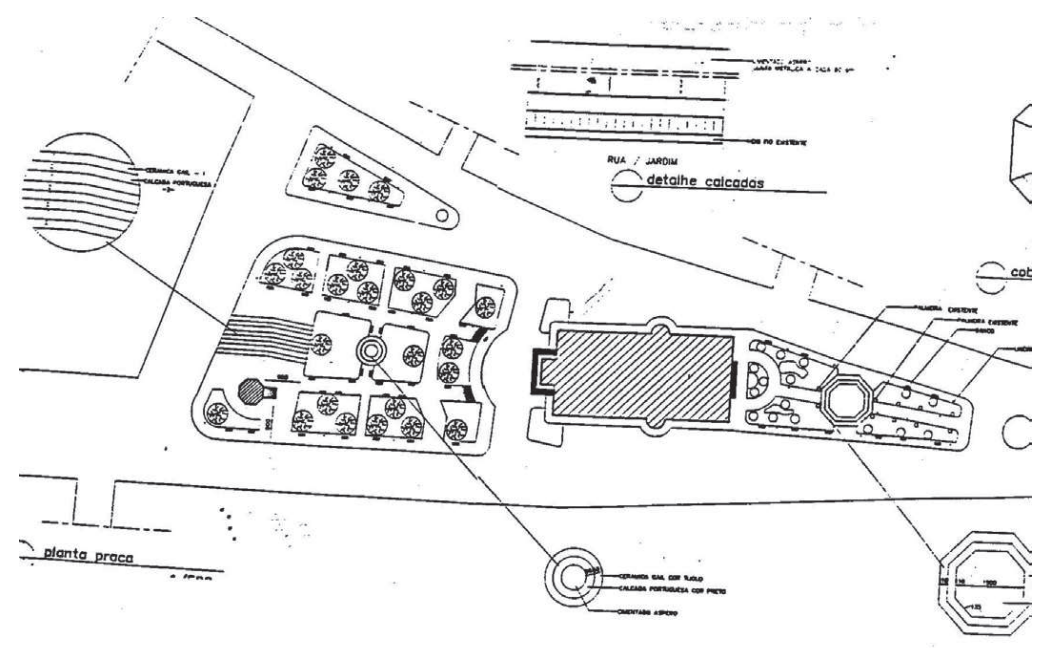

Figura 9: Praça Matriz por volta da década de 1950 Fonte: Prefeitura Municipal de Santo Antônio do Amparo

Atualmente podemos considerar que a praça tem usos mais diversificados além daqueles do estilo eclético (passeio, contemplação da natureza, convívio social e cenário) como: recreação, comércio, serviços e circulação.

\section{Espacialização do território}

\section{Área de influência}

As praças Governador Valadares e Joaquim Ferreira representam o centro de um espaço que interliga entre os principais monumentos e edificações de valor histórico e cultural do município de Santo Antônio do Amparo, gerando uma influência direta na dinâmica da cidade, abrigando os principais serviços, comércios e tráfego, e gerando, conseqüentemente, um fluxo intenso de pessoas e veículos.

\section{Morfologia do espaço}

O espaço está implantado em local alto e montanhoso, em um largo com ligeira inclinação (aproximadamente 5\%) descendente formando um eixo único que liga visualmente a praça à todo o contorno da área central do município, através das principais edificações históricas.

O conjunto das praças com a Igreja Santo Antônio do Amparo tem a forma triangular, sendo a igreja central. Essa idéia de conjunto não é muito perceptível devido à fragmentação das praças. Porém, todas elas possuem a mesma paginação de piso (filetes de calçada portuguesa nas cores preta, vermelha e branca e cimento) e o mesmo tipo de vegetação e mobiliário urbano.

As praças são uma organização espacial intencional, um lugar de encontro, a partir de um desenho urbano e atuam na amenização do ritmo paisagístico das edificações, oferecendo o verde ou locais de descanso, e contribuindo fortemente para uma harmonização de seu entorno.

De destaque na praça Joaquim Ferreira, a imagem do Cristo Redentor é um elemento de morfologia singular pelo seu posicionamento, configuração e de significado na paisagem, marcando o eixo central da avenida Santo Antônio e a torre da Igreja Matriz.

\section{Vegetação}

As praças Governador Valadares e Joaquim Ferreira apresentam uma diversificada vegetação, que varia desde de pequenos arbustos até grandes árvores. Tal conformação vegetativa configura um espaço sombreado, que ajuda, dessa forma, em sua função de espaço público de estar. 
A vegetação se conforma em canteiros aleatoriamente distribuídos, com pequena proteção de concreto. Entres esses canteiros existem mobiliários urbanos como bancos, lixeiras e postes de luz.

\section{Sistema viário}

A conformação é dada pela avenida Santo Antônio, a via arterial de todo complexo, pela qual se dá o escoamento de grande parte do trânsito da cidade. Paralela a esse eixo há outra rua complementar, avenida José Ananias, que serve de via local. E por sua vez, as vias perpendiculares desempenham a função de vias afluentes e efluentes.

A avenida Santo Antônio é dividida em duas mãos, sendo as ruas menores de sentido viário duplo.

Essa estrutura de trânsito atende bem ao fluxo de veículos do município, indicando uma boa articulação de projeto nesse sentido.

\section{Tipologia das edificações do entorno}

O entorno das praças Governador Valadares e Joaquim Ferreira é diversificado quanto às edificações e seus usos. A maioria é compreendida por edificações horizontais unifamiliares de uso residencial, mas também existem na espaço edificações para prestação de serviços como o banco Itaú, o que, juntamente com o comércio local, tornam intenso o uso da praça, tanto por pessoas que usufruem o espaço público, ou transeuntes, que utilizam o mesmo como caminho.

Compondo o entorno, ainda há o edifício da Casa da Cultura, que traz para a praça o uso de vários eventos relacionados à vida cultural local, tais como feiras e amostras.

No encontro das praças está localizada a Igreja Santo Antônio do Amparo, de estilo clássico, com uma alta torre marcando a entrada frontal. Essa entrada é feita através de uma escada ou duas rampas laterais. $O$ revestimento da fachada é de pintura nas cores amarelo e branco.

\section{Identidade e valor cultural}

Há algumas edificações de valor histórico no entorno do espaço, sendo elas exemplos de construções coloniais e ecléticas, que mantêm essas características até hoje. Infelizmente, em algumas residências essas características já foram alteradas, podendo-se observar apenas vestígios delas como esquadrias de ferro, telhado colonial, entre outros. Algumas edificações já não possuem valor histórico e cultural, foram construídas mais recentemente. Em alguns lotes há apenas muros, indicando que alguma edificação fora demolida e/ou vai ser construída.

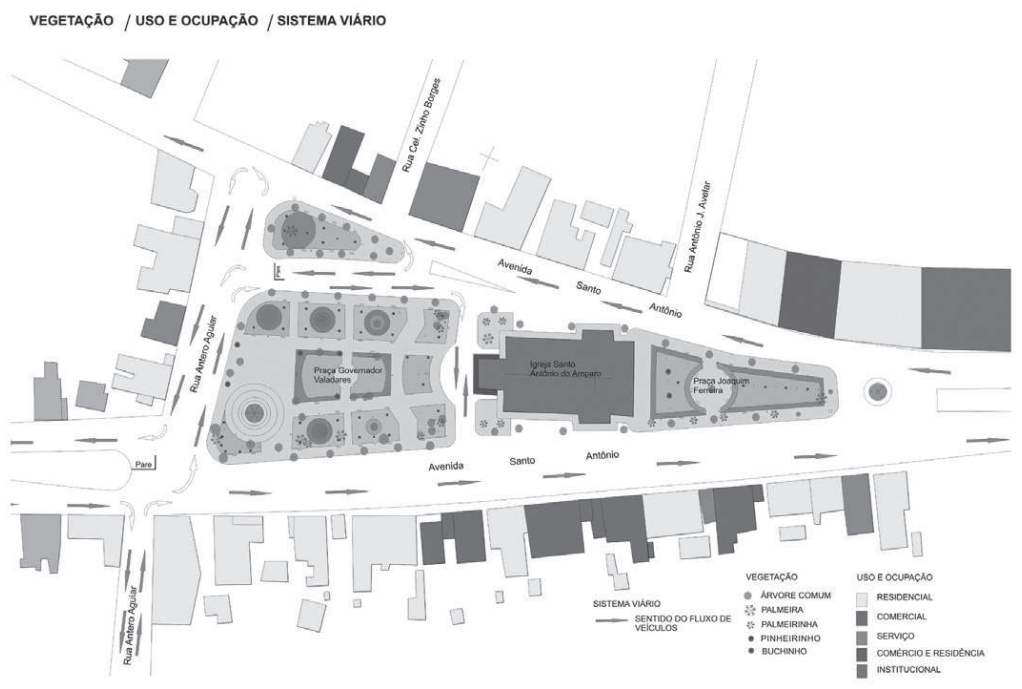

Figura 10: Mapa de vegetação/ sistema viário/uso e ocupação Fonte: Karina Machado de Castro Simão e Stefânia de Araújo Perna 
Considerando a área central, em geral, de relevância histórica e cultural para Santo Antônio do Amparo, as praças Governador Valadares e Joaquim Ferreira mantêm sua identidade visual e histórica ao longo do tempo, e têm, assim, grande importância para a cidade e seus moradores. Isso é percebido através do constante uso do local, que propicia à população (de todas as camadas sociais) usar, de modo adequado, o tempo livre que dispõe para realização de atividades físicas e descanso mental e desenvolvimentos pessoais, sociais e culturais nas praças.

\section{Uso do local}

As praças têm uma diferente apropriação de uso, que varia de espaço de circulação, espaço de descanso, local para eventos, entre outros. Mas a principal função é incentivar a vida comunitária.

A praça Governador Valadares é formada por um amplo espaço sombreado, devido às grandes árvores, que conforma, assim, um espaço de convivência. Já a praça Joaquim Ferreira possui um pequeno espaço de estar, mas suficiente para atender a população. Tais espaços ainda são reforçados pela existência de vários bancos.

Durante o dia, esses espaços são povoados por idosos e aposentados, sendo usados como ponto de encontro e sociabilidade, e também por trabalhadores do comércio e seus usuários, além dos alunos da escola próxima, que usam sempre o local para passagem. Durante a noite, a praça é bastante utilizada, principalmente nos fins de semana, devido à existência do coreto e de um restaurante e bares ao redor, que servem de ponto de encontro das pessoas. Os eventos e as festas ocorrentes no local utilizam, geralmente, o espaço do coreto.

Foi observado que as maiores concentrações de pessoas estão vinculadas diretamente ao uso da lgreja Matriz.

\section{Equipamentos urbanos}

A praça Governador Valadares possui como equipamento urbano de grande porte apenas o coreto, que contribui para uma harmoniosa ocupação dos usuários das praças. É importante salientar que nesse coreto há um banheiro público para a comunidade, que é um suporte às atividades a serem desenvolvidas no espaço.

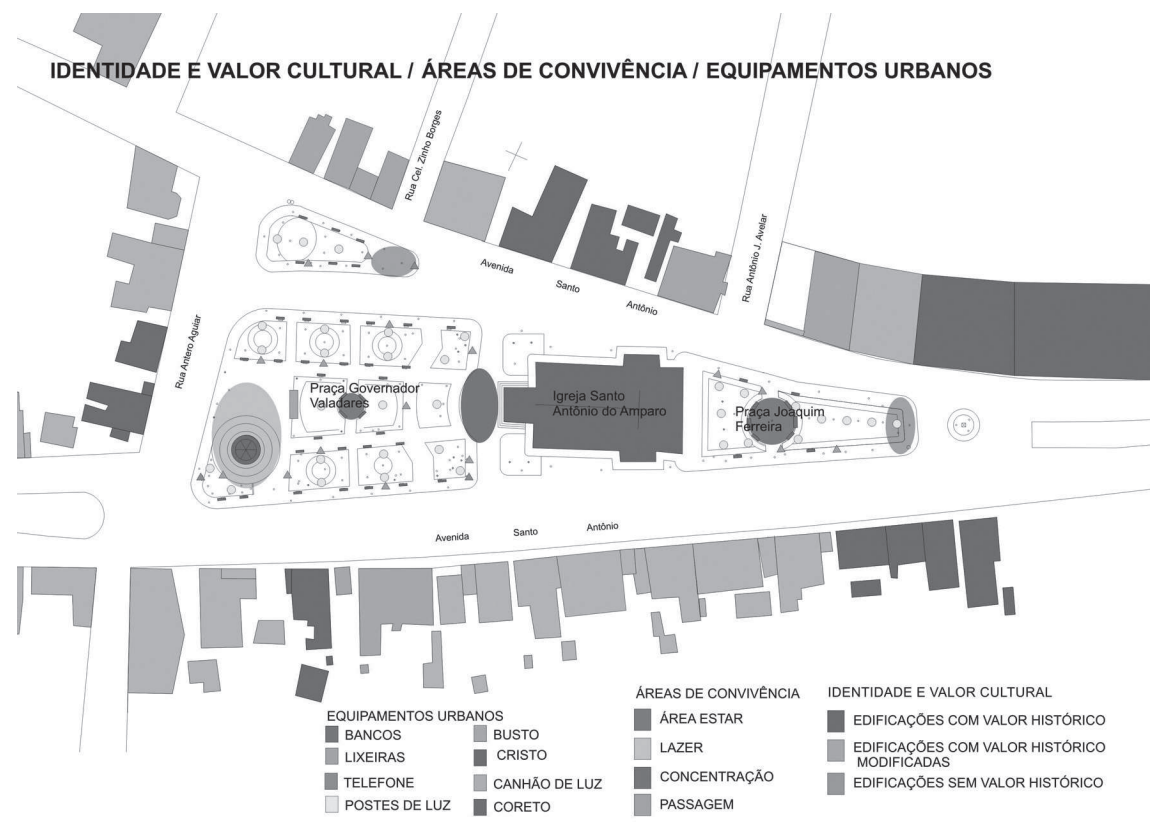

Figura 11: Mapa de identidade e valor cultural/ áreas de convivência/ equipamentos urbanos Fonte: Karina Machado de Castro Simão e Stefânia de Araújo Perna 
Em ambas as praças o espaço público é bem iluminado durante a noite, já que os postes de luz são bem distribuídos. Quanto às lixeiras, há várias delas, sendo mais que suficientes para o lixo produzido ao longo do dia. Há poucos telefones públicos, mas mesmo assim atendem bem às demandas da população. Não há bancas de revista no espaço, tornando-o mais limpo.

As praças possuem alguns bancos de estilo clássico, bem distribuídos, mas insuficiente para atender a demanda da população.

\section{Diagnóstico geral: identificação dos problemas}

A partir do estudo do espaço percebe-se que a praça Joaquim Ferreira transformou-se em ponto de convergência do fluxo de pedestres e necessita de configurações formais que favoreçam e permitam a distribuição e a circulação dos transeuntes. A praça Governador Valadares, que recebe enormes quantidades de pessoas, principalmente em dias de festas, também deve acomodar o crescente movimento de pedestres.

Temos assim um espaço fragmentado que não atende aos pedestres do município. A estruturação do sistema viário segrega as praças e, dessa forma, o veículo tem maior prioridade do que o próprio pedestre. Essa segmentação atrapalha a acessibilidade e entendimento do espaço como único: a idéia de largo da igreja não existe mais.

Podemos citar como aspectos positivos do local: o bom uso da praça (que está constantemente povoada), o bom estado de conservação dos equipamentos urbanos (bancos, lixeira, canteiros), e a boa arborização do local. Como aspectos negativos temos: excesso de alguns mobiliários urbanos, como lixeiras e bancos; a depredação dos postes de iluminação, e a falta de manutenção dos jardins e canteiros.

Esse estudo mostra a necessidade de uma intervenção tanto na malha viária quanto na estruturação da praça para melhorar a sua configuração, principalmente no que diz respeito à distribuição de canteiros (busca de melhor harmonia).

A intervenção também será importante para promover uma melhor articulação e gerar um apoio ao espaço em relação aos eventos que ali ocorrem, como feiras, manifestações e festas.

\section{Proposta paisagística}

O conceito do projeto é baseado na criação de um espaço uniforme, com ambientações internas bem definidas e integradas, mas também multifuncionais e adaptáveis, capazes de permitir os mais variados usos, sem ter uma função determinada.

O projeto objetiva melhorar a acessibilidade e valorizar o pedestre, através da alteração do sistema viário e conseqüente mudança dos espaços de circulação de carros para espaços de passagem para as pessoas, já que as praças são muito freqüentadas pela população local.

Além disso, a proposta para a revitalização da praça da Matriz, segue os conceitos e as necessidades contemporâneas, que visa criar novos espaços que contemplem as seguintes atividades:

- Lazer contemplativo;

- Lazer ativo (recreação infantil, atividades esportivas e culturais);

- Lazer cultural;

- Convívio Social;

- Equipamentos de apoio às atividades comerciais e de serviços (utilitarismo);

- Circulação;

- Cenário. 
Essa implantação de espaços com uso flexível possibilita ao freqüentador apropriar-se do projeto da maneira que lhe for mais agradável e necessária. Além disso, permite a participação da comunidade na dinâmica da cidade, de modo a rebater as imposições de comportamento, utilização e apropriação dos espaços livres públicos, tão comuns na arquitetura paisagística moderna.

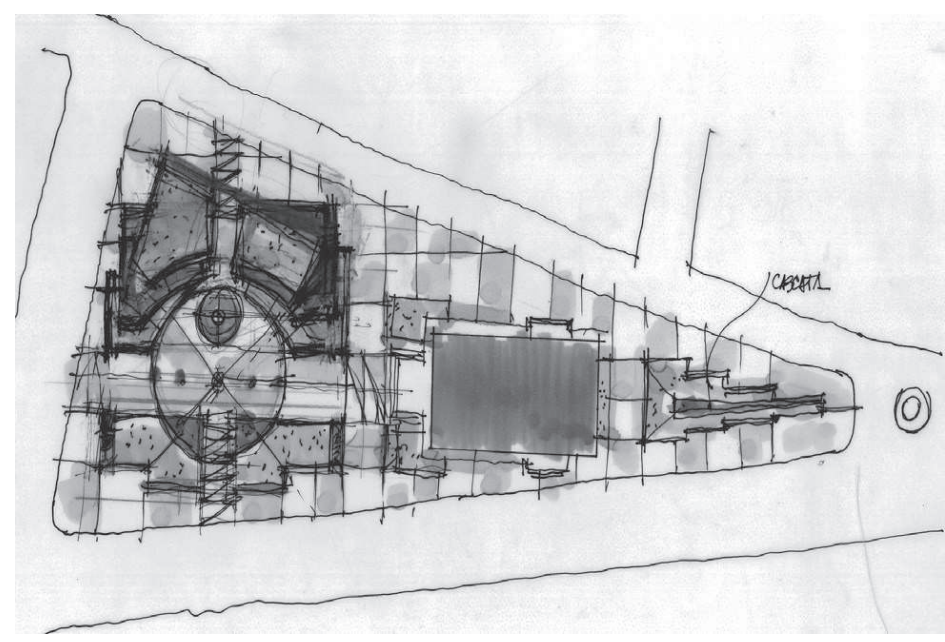

Figura 12: Croqui de estudo - Planta Fonte: Marieta Cardoso Maciel

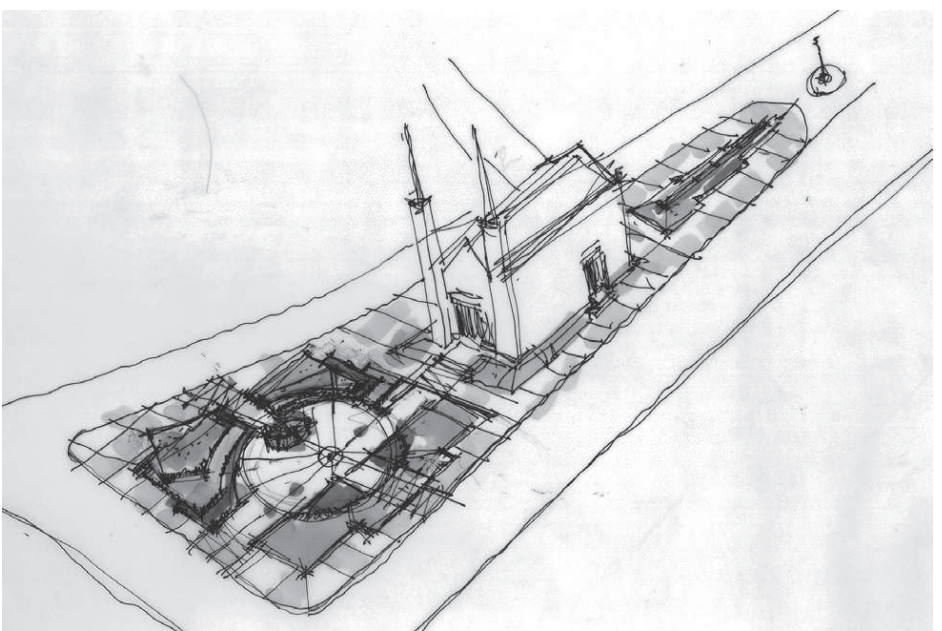

Figura 13: Croqui de estudo - Perspectiva Fonte: Marieta Cardoso Maciel

Mesmo que se considerem parâmetros e conceitos contemporâneos, e traga uma expressão plástica para o espaço, a proposta para a revitalização da praça da Matriz remete ao passado e busca manter o estilo clássico (já existente), através do uso da simetria e de formas geométricas.

A simetria é marcada pelo eixo longitudinal do espaço, que coincide com o eixo da igreja de Santo Antônio do Amparo. Esse eixo de percurso e de visada marca a entrada da igreja e é o ponto referencial para a concepção do projeto.

Na praça Governador Valadares, o caminho da rua até a entrada da lgreja ressalta esse eixo, que é enfatizado também por elementos paisagísticos e arquitetônicos como as fontes secas, espelhos d'água e paginação do piso. Uma esplanada é proposta no centro desse caminho, e sugere um ambiente de lazer e recreação, com o coreto e bancos próximos aos canteiros. É também proposta a implantação de um espaço aberto e amplo, que permita a reunião de amigos ou ocorrência de jogos nas proximidades dos bares e restaurantes ali existentes, que visa majorar o uso e ocupação do espaço.

Na praça Joaquim Ferreira a proposta do canteiro remete diretamente ao desenho do canteiro na década de 1950, havendo uma inversão dos espaços verdes e secos e a inserção de um filete d'água, que destaca (novamente) o eixo longitudinal do espaço e da igreja. 

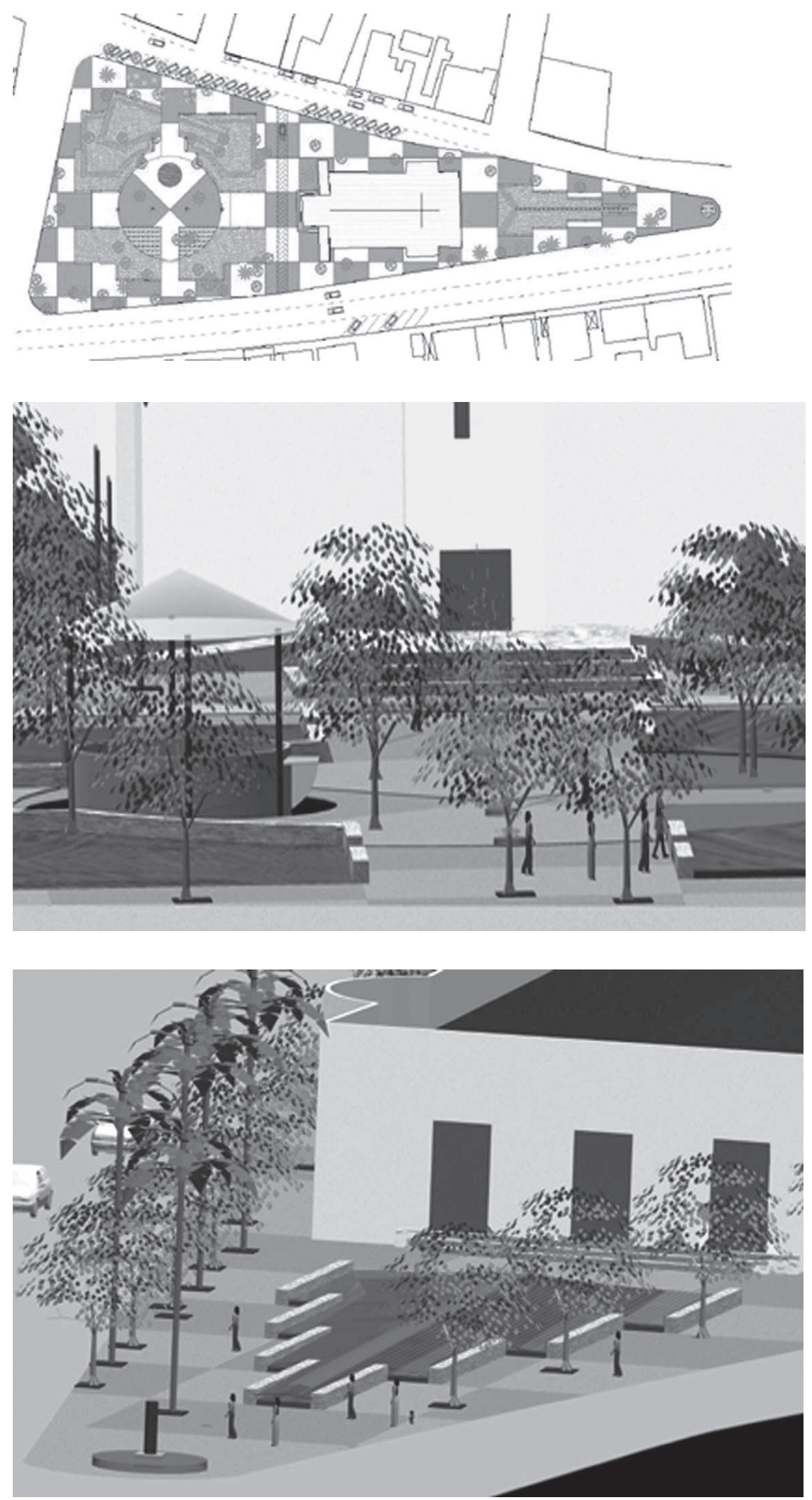

Figura 14: Proposta - Planta Fonte: Karina Machado de Castro Simão e Stefânia de Araújo Perna
Figura 15: Vista de eixo longitudinal para a igreja Fonte: Karina Machado de Castro Simão e Stefânia de Araújo Perna
Figura 16: Vista da praça Joaquim Ferreira Fonte: Karina Machado de Castro Simão e Stefânia de Araújo Perna

O projeto, além de ressaltar a Igreja, contempla os espaços de convivência e lazer, mantem os mesmos espaços atualmente utilizados e amplia alguns deles.

Além disso, a proposta visa a circulação de pedestres, através do alargamento dos passeios e unificação das praças. A necessidade de espaço para absorver a enorme quantidade de pessoas em trânsito nas praças, situadas no centro da cidade, revaloriza a figura da praça seca em alguns locais do espaço. 
Apesar de manter o conceito clássico, a nova proposta busca renovar o estilo para contemporâneo através de mudanças das características do mobiliário urbano (coreto, bancos, postes, canteiros, entre outros) e dos materiais de revestimento. A paginação simétrica do piso permite usar como material, placas de granito apicoado ou placas de concreto.

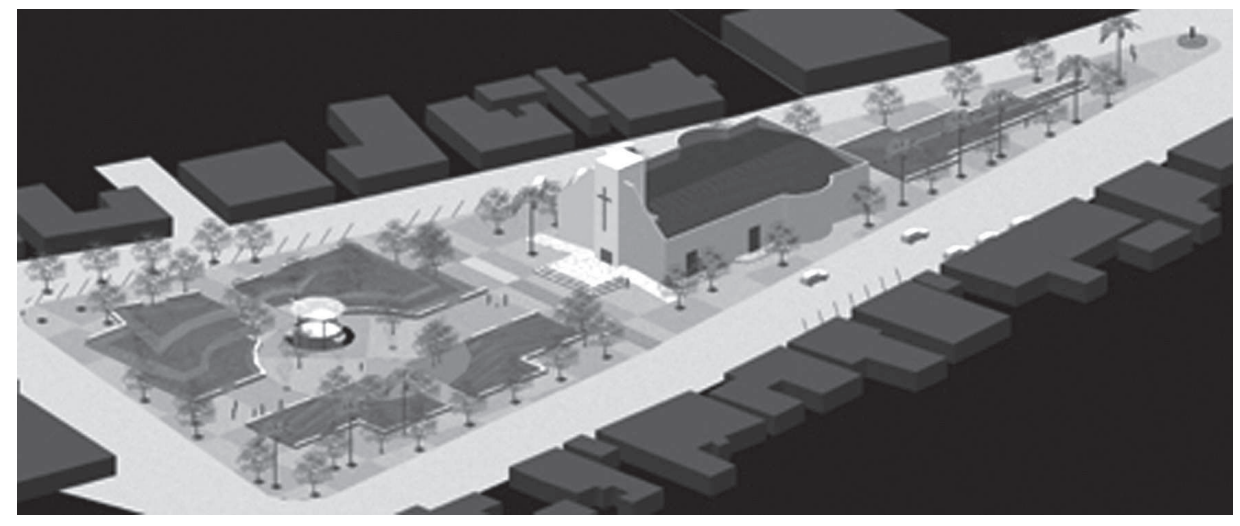

Figura 17: Vista geral do espaço Fonte: Karina Machado de Castro Simão e Stefânia de Araújo Perna

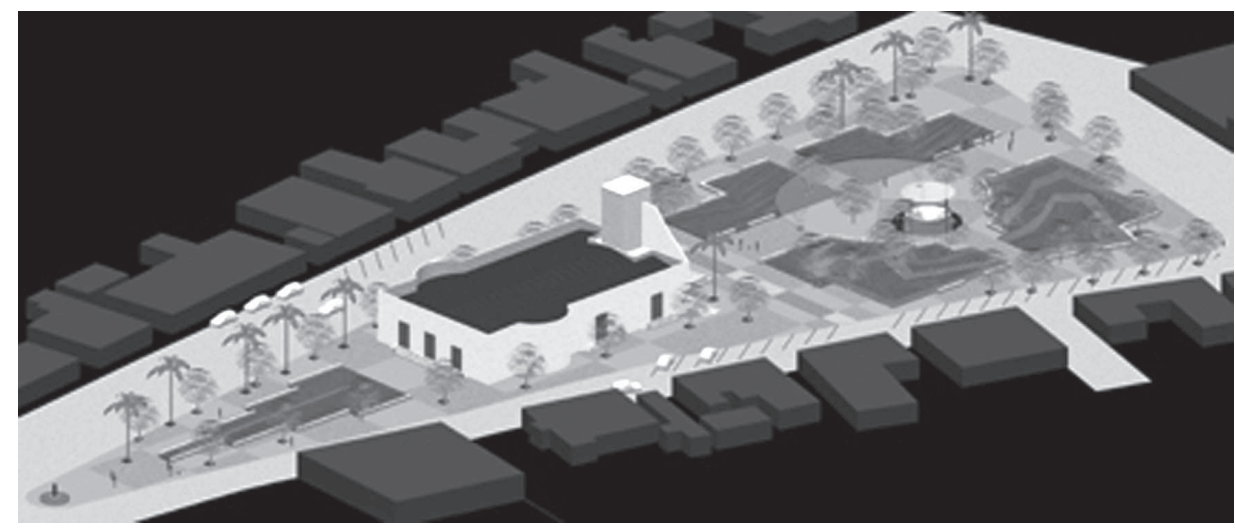

Figura 18: Vista geral do espaço

Fonte: Karina Machado de Castro Simão e Stefânia de Araúio Perna

\section{Conclusão}

O Programa de Arquitetura Pública adota a experimentação prática, como meio para ensinar e complementar o ensino através de situações reais que abrangem algumas especificidades da arquitetura e do urbanismo - o projeto, o planejamento urbano, a preservação e conservação do patrimônio cultural - e, a partir dessa experimentação, a geração de demandas para a pesquisa.

Pretende-se, dessa forma, complementar a formação do estudante tanto do ponto de vista acadêmico, como sócio cultural.

Essa experiência foi adquirida durante a elaboração da proposta de revitalização da praça Matriz do município de Santo Antônio do Amparo, que visa melhorar o aspecto funcional e estético da praça existente, através de conceitos contemporâneos e do uso de formas clássicas e prima pelo desenvolvimento urbano do município, e, conseqüentemente, pelo bem estar de sua população.

Dessa forma, os alunos envolvidos no programa adquiriram experiência projetual na elaboração de projetos de espaços públicos e paisagismo, além de aprenderem o valor das praças para municípios, principalmente os de pequeno porte, como Santo Antônio do Amparo.

O programa tem tido sucesso nas cidades envolvidas em geral. Em Santo Antônio do Amparo, a aceitação da proposta de revitalização da praça matriz foi unânime tanto pela comunidade quanto pela administração. A audiência pública para apresentação do projeto à comunidade teve grande repercussão na cidade, com presença significativa dos cidadãos amparenses e dos jornalistas locais, que publicaram nota sobre o projeto no jornal da cidade (ver Figuras 19 e 20). 


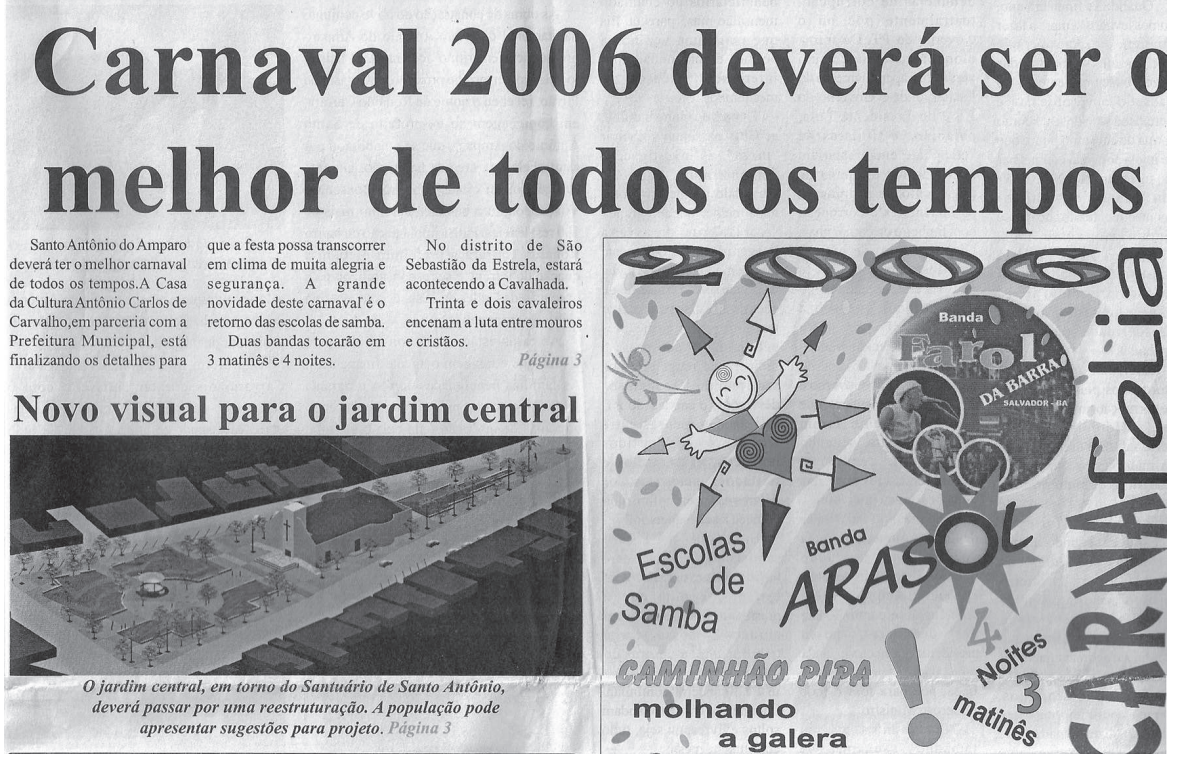

Figura 19: Artigo sobre a assembléia de apresentação do projeto de revitalização da praça Matriz

Fonte: Jornal Folha Amparense - fevereiro de 2006

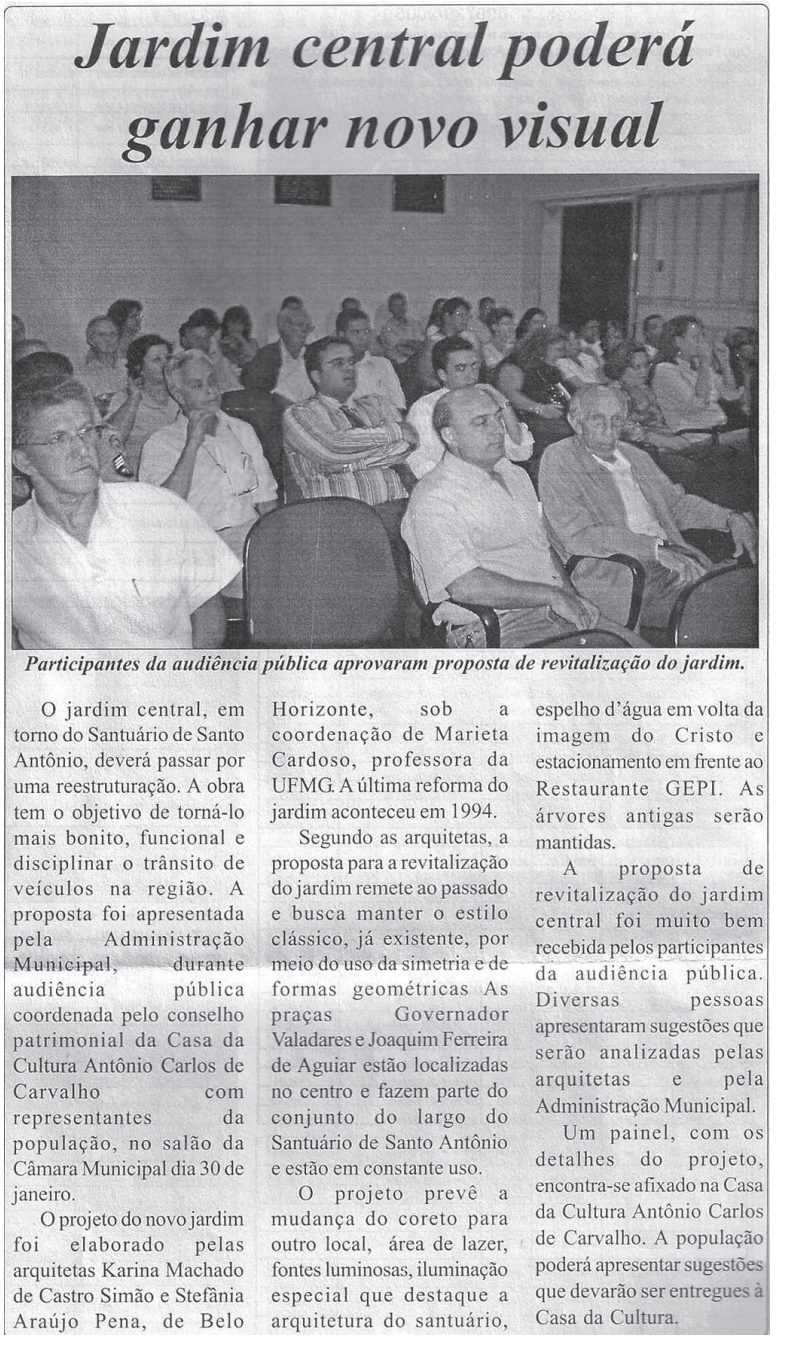

Figura 20: Artigo sobre a assembléia de apresentação do projeto de revitalização da praça Matriz

Fonte: Jornal Folha Amparense - fevereiro de 2006 


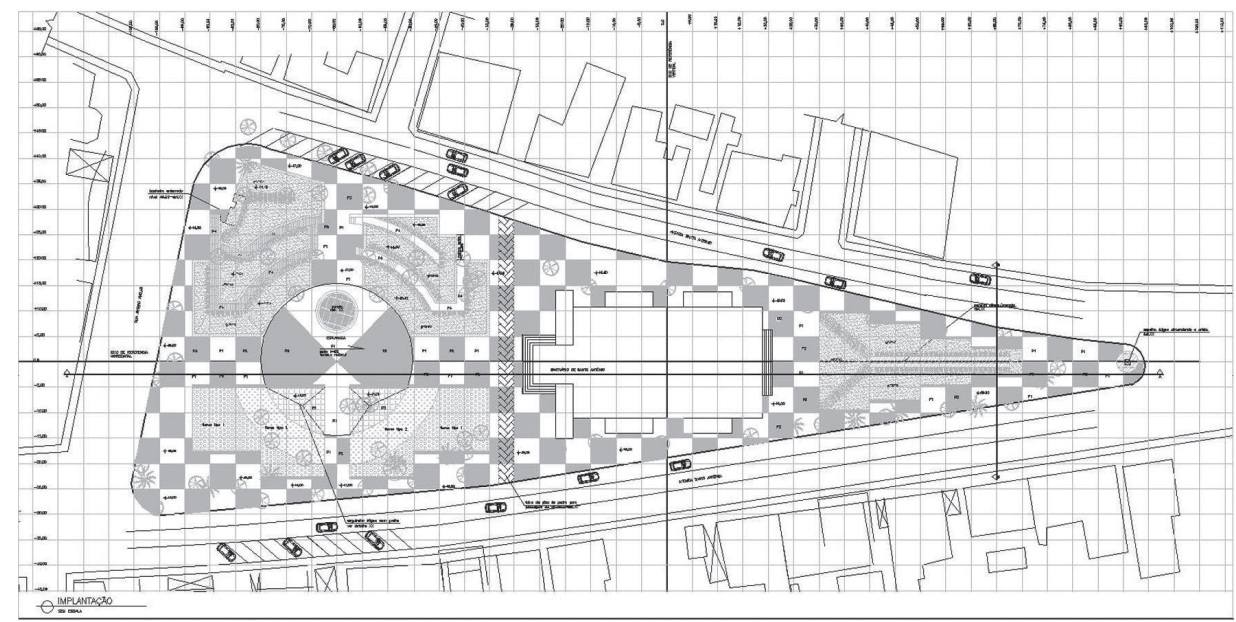

Figura 21:

Projeto executivo

- Implantação

geral

Fonte: Karina

Machado de

Castro Simão e

Stefânia de Araúio

Perna

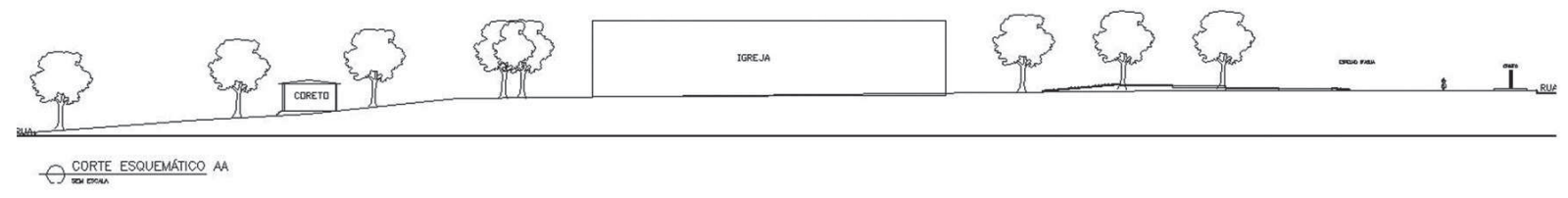

Figura 22: Projeto executivo - Corte Esquemático AA

Fonte: Karina Machado de Castro Simão e Stefânia de Araújo Perna

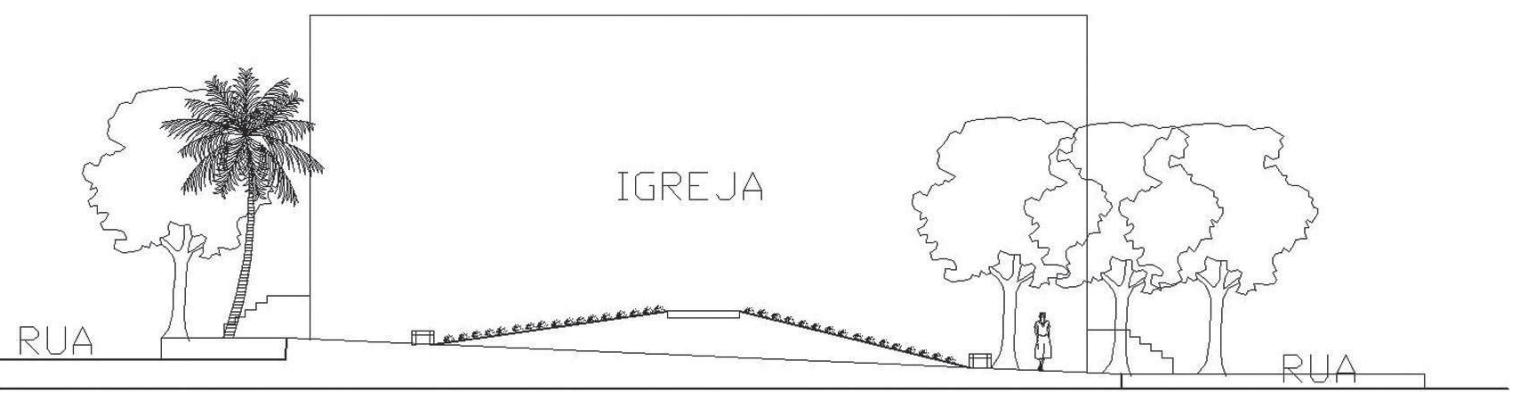

Figura 23: Projeto executivo - Corte Esquemático BB

Fonte: Karina Machado de Castro Simão e Stefânia de Araújo Perna

No caso de Santo Antônio do Amparo, o programa cumpriu um de seus papéis, que é o de inserir os alunos nos problemas reais do paisagismo. As alunas, antes bolsistas do programa, foram contratadas pela prefeitura, e já estão elaborando o projeto executivo para a praça Matriz, além de outros projetos demandados pela administração municipal, e são requisitadas por cidades vizinhas carentes do profissional de arquitetura.

\section{Bibliografia}

212 CHACEL, Fernando Magalhães. Projetos de praças. São Paulo: ABAP, [19,-?].

Espaços urbanos e praças. São Paulo: ABAP, [19,-?].

HOLDEN, Robert. Diseno del espacio publico internacional. Barcelona: Gustavo Gilli, 1996. 
LEITÃO, Lúcia. As praças que a gente tem, as praças que a gente quer: Manual de procedimentos para intervenção em praças. Recife: Secretaria de Planejamento. Diretoria de Urbanismo, 2002.

MACEDO, Silvio Soares. Quadro do paisagismo no Brasil. São Paulo: Fapesp / CNPq/Laboratorio da Paisagem, v. 31 , n. 10, 1996, 1999

MACIEL, Marieta Cardoso; GUEDES SOBRINHO, Joaquim. O projeto em arquitetura paisagística: Praças e parques públicos de Belo Horizonte. 1998. 255p. Tese (Doutorado) - Faculdade de Arquitetura e Urbanismo, Universidade de São Paulo, São Paulo, 1998.

ROBBA, Fabio. Praças brasileiras. 2. ed. São Paulo: Edusp/Imprensa Oficial do Estado de São Paulo, 2003.

\section{Fontes}

Entrevista com o sr. Pedro Alves de Avelar, em 14 de outubro de 2005.

Plano de Inventário para o Município, em 2004.

Texto sobre Arquitetura Pública - Arquiteto Eduardo Fajardo, Escola de Arquitetura, UFMG, 2005.

Texto sobre Arquitetura Pública - Arquiteto Paulo Henrique Alonso, Escola de Arquitetura, UFMG, 2006.

<http://www.geocities.com/santoantonioamparo/principal.html>, em outubro de 2005. 